\title{
A feasible synthetic strategy for three-armed star poly(ester amine) via Michael addition polymerization
}

\author{
Wei Yang, Cai-Yuan Pan * \\ *Department of Polymer Science and Engineering, Joint Laboratory of Polymer Thin \\ Films and Solution, University of Science and Technology of China, Hefei, Anhui \\ 230026, People's Republic of China; email: pcy@ustc.edu.cn.
}

(Received: 01 May, 2008; published: 17 February, 2009)

\begin{abstract}
Three-armed star-shaped poly(ester amine) was synthesized by Michael addition polymerizations of equal molar ratio of ethylene glycol diacrylate (EGDA) and piperazine (PZ) in the presence of a small amount of multifunctional monomer, 1,3,5-triacryloylhexa-hydro-1,3,5-triazine (TT) in $\mathrm{CHCl}_{3}$. When the polymerization proceeded almost completely, the molecular weight of the polymers formed were determined by the feed molar ratio of difunctional monomer to multifunctional monomer, and the molecular weight distribution $\left(M_{\mathrm{w}} / M_{\mathrm{n}}\right)$ approached the theoretical value $\left(M_{\mathrm{w}} / M_{\mathrm{n}}=1+1 / f\right)$. The mechanism of the polymerization was investigated by ${ }^{1} \mathrm{H}$ NMR and Gel permeation chromatography (GPC). The monomer concentration and the molar ratio of difunctional monomers/multifunctional monomer played an important role in the polymerization.

Key words: star-shaped poly(EGDA-PZ); Michael addition polymerization; one-pot synthesis.
\end{abstract}

\section{Introduction}

Design and synthesis of star polymers are of considerable interest due to their interesting rheological properties and multi terminal functionalities in comparison with the linear analogue [1,2]. Generally there are three synthetic strategies of star polymers: (1) the core-first method involves the use of a multifunctional initiator to initiate living polymerization resulting in polymers with well-defined structures [3, 4]; (2) the arm-first method involves the synthesis of living linear arms, following reaction with a multifunctional coupling agent [5, 6]; (3) crosslinking reagent method involves a living polymerization in the presence of a small amount of crosslinking reagent such as divinyl monomer $[7,8]$. In comparison with these methods, synthesis of starshaped polymers from condensation polymerization of A-B monomer in the presence of a multifunctional compound, $A_{f}(f$ is the number of functional group, $f>3$ ) was less studied [9-12]. In these reports, the star-shaped polymers included aromatic polyamides from polycondensation of phenyl 4-(octylamino)benzoate and tri- or tetraphenyl aromatic ester [9]; aromatic polyesters from silylated $\beta$-(4-acetoxyphenyl) propionic acid, silylated 4-acetoxybenzoic acid and tetraacetoxyspirobis(indane) [11]; poly(arylene ethynylene) from 2,5-diiodo-3- hexylthiophene, $p$-diethynylbenzene and triethynyl- or tetraethynylbenzene [12]. In these polymerizations, the competition reactions between propagation reactions of the linear chains and star polymer chains existed, leading to the multi peaks in GPC traces of the resultant products [12]. Therefore purification process is necessary for preparation of pure star-shaped polymers. These results showed that polycondensation is not appropriate for the synthesis of well-defined star-shaped polymers because it does not proceed in a 
chain polymerization manner [9]. According to the theoretical prediction, the starshaped polymers have the arm number exactly as same as the number of functional groups in the multifunctional reactant used, and average chain length of every arm is controlled by the proportion of multifunctional unit employed [13, 14]. The polycondensation of $A-B$ and multifunctional compound should be an appropriate method for preparation of well-defined star-shaped polymers.

The poly(ester amine)s have been studied extensively due to their potential applications in drug deliverey and gene transfection [15-17], and we previously studied the synthesis of various poly(amido amide)s at mild conditions [18-20]. Thus, to test whether polycondensation of $A-A, B-B$ and a small proportion of $A_{f}$ yields wellcontrolled polymer, we studied Michael addition polymerization of diacrylates (A-A) and diamine $(B-B)$ in the presence of a triacrylate compound $\left(A_{3}\right)$ to form star-shaped poly(ester amide) because these reactants are commercially available and polymerization can be carried out at mild conditions. In this article, we report our study on the polymerization behaviors of poly(ethylene glycol) diacrylate $\left(A_{2}\right)$ and piperazine $\left(B_{2}\right)$ in the presence of 1,3,5-triacryloylhexa-hydro- 1,3,5-triazine $\left(B_{3}\right)$.

\section{Results and Discussion}

\section{Synthesis of Star poly(EDGA-PZ) with TT}

A convenient strategy for synthesis of star-shaped polymers is addition of a multifunctional compound into polycondensation of $A-A$ and $B-B$. For the polymerization system consisting of bifunctional monomer, $A-B$ and a small proportion of a multifunctional compound, $\mathrm{R}-\mathrm{A}_{f}(f$ is the number of functional group A), and assuming that the terminal group A, or B cannot react itself, the crosslinking reaction should be precluded in principle, according to Flory's theory $[13,14]$. The polymers formed will consist of $f$ polymer chains attached to the central units $\mathrm{R}$, and their formula can be written as $R\left[-A(B-A)_{y}\right]$, and the average chain length of every arm can be controlled by the proportion of multifunctional unit employed. Therefore, the arm number and chain length of every arm are controlled. In this study, we selected ethylene glycol diacrylate (EGDA) and piperazine (PZ) as A-A and B-B monomers respectively because the Michael addition reaction of acryl of EGDA with secondary amine of $P Z$ is possible, and their addition polycondensation with equal molar ratio of EGDA and $P Z$ yields a linear poly(EGDA-PZ) with one terminal acryl (A) group and one terminal secondary amine (B) group. TT with three acryl groups was used as $A_{f}(f=3)$. The synthesis of star-shaped polymers is outlined in Scheme 1. For investigation of the polymerization behavior, the polycondensation of equal molar EGDA and PZ in the presence of TT was carried out, and ${ }^{1} \mathrm{H}$ NMR was used to follow the polymerization. A typical ${ }^{1} \mathrm{H}$ NMR spectrum is shown in Figure 1 . The terminal vinyl proton signals of acryl groups appeared at $\delta=6.38,6.15,5.86 \mathrm{ppm}(\mathrm{a})$, the proton signals of the ester methylene, the methylene groups next to nitrogen and next to ester carbonyl groups appear at $\delta=4.28$ (c), 2.17-2.80 ppm (d, e). The signal at $\delta=5.25 \mathrm{ppm}$ (b) is ascribed to three methylene groups of hexahydro-1,3,5-triazine ring. These facts indicated that the linear poly(ester amine)s attached to the multifunctional compound, TT. Based on the ${ }^{1} \mathrm{H}$ NMR data in Figure 1, we can calculate the conversion (vinyl\%) of the double bonds in EGDA and TT according to Eq. 1. 
vinyl\% $=\left(1 £-\frac{\left(I_{6.38^{-5} .86}\right) / 3}{\left(I_{4.28} / 4\right)+\left(3 I_{5.25} / 2\right)}\right) \mathrm{i} \dot{A} 100 \%$

Here, $I_{6.38-5.86}, I_{5.25}$ and $I_{4.28}$ are the integral values of proton signals at $\delta=6.38,6.15$ and $5.86(\mathrm{a}), 5.25(\mathrm{~b})$ and $4.28 \mathrm{ppm}(\mathrm{c})$.<smiles>[R2]C=CC(=O)OCCOC(=O)C=C[CH+]</smiles>

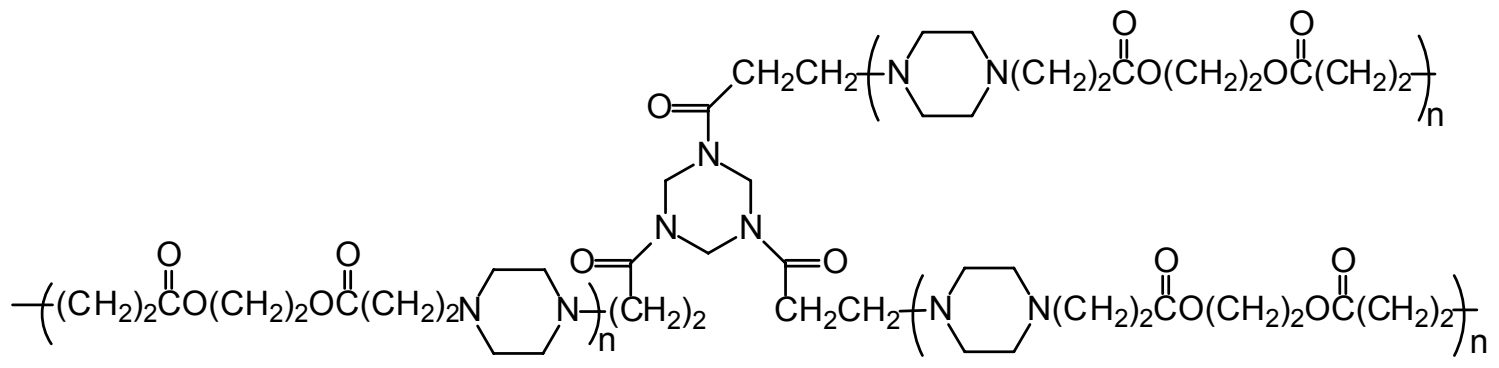

Scheme 1. The synthesis of star-shaped poly(ester amine) from EDGA, PZ and TT.

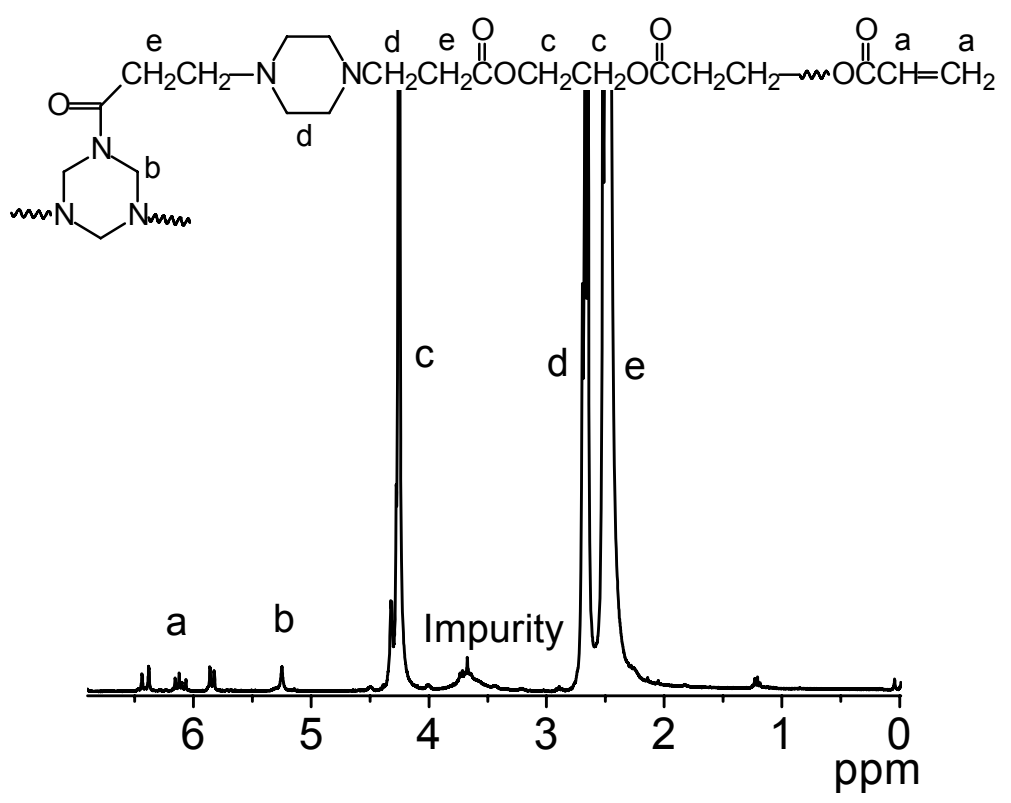

Fig. 1. A typical ${ }^{1} \mathrm{H}$ NMR spectrum of star-shaped poly(EDGA-PZ-TT).

We can see that the vinyl groups disappeared relatively fast (Figure 2A) at the initial stage of polymerization, and after $50 \mathrm{~h}$ of polymerization the disappearance rate of vinyl group became slow. However the molecular weight increase rate of the polymers formed was relatively slow before $95 \%$ conversion, and then became fast after $95 \%$ conversion (Figure 2B). This is the characteristics of step polymerization. 

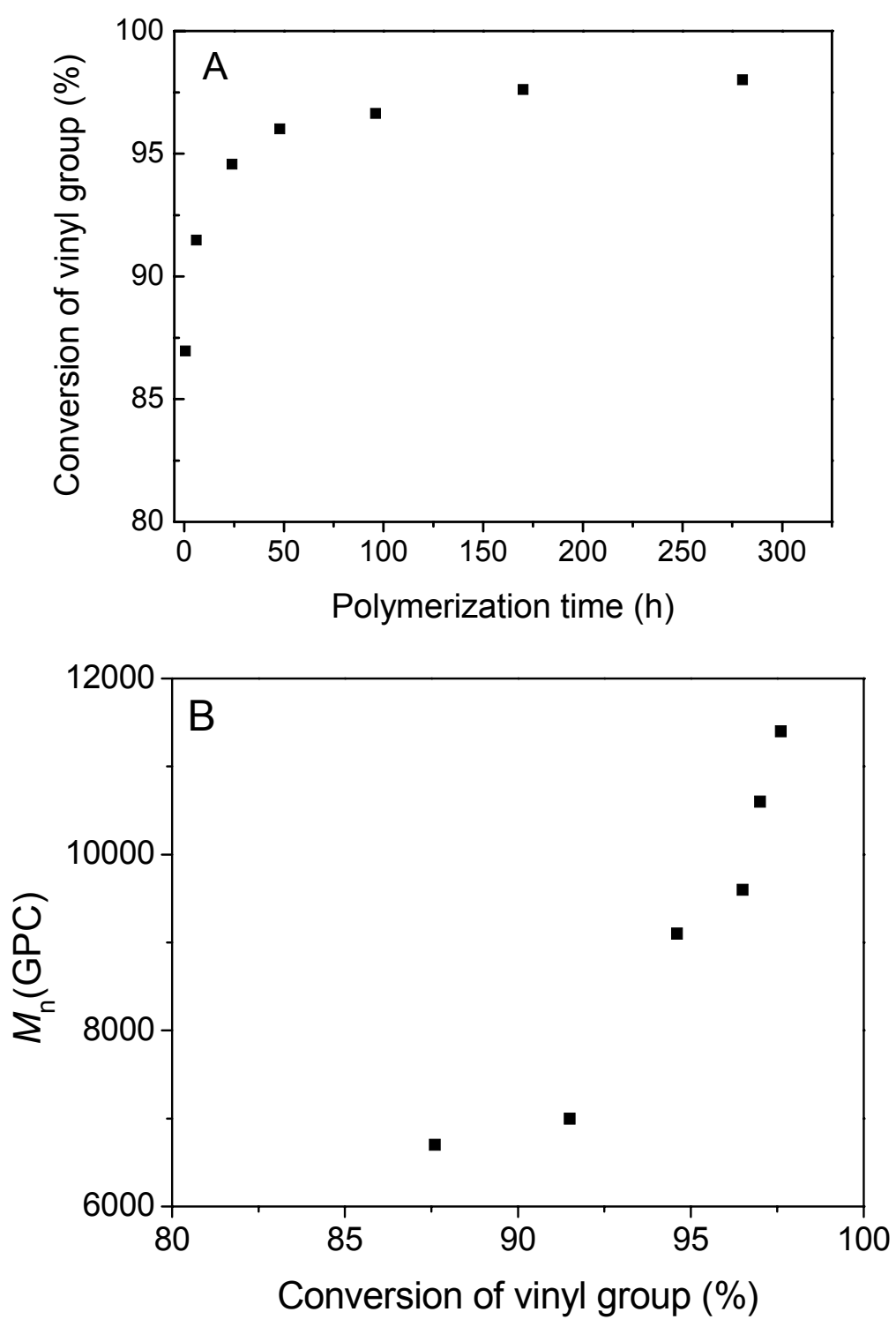

Fig. 2. The relationship of vinyl group conversion with polymerization time $(A)$ and the dependence of molecular weight on conversion of vinyl group (B). Feed molar ratio of TT/EGDA/PZ=1/60/60; Concentration of monomer: $30 \%(w / v)$; Temperature: $45^{\circ} \mathrm{C}$; Solvent: $\mathrm{CHCl}_{3}$.

In order to investigate the formation process of star polymers, the GPC was used to follow the polymerization at $45^{\circ} \mathrm{C}$ with feed molar ratio of TT/EGDA/PZ=1/60/60. The results are shown in Figure 3. The GPC trace of the polymer formed at $0.5 \mathrm{~h}$ of polymerization in Figure $3 a$ is monomodal, probably this is ascribed to the linear poly(ester amine) because a small percent of multifunctional compound, TT was added into the polymerization system, the Michael addition polymerization of EGDA and PZ to produce linear poly(ester amine) was predominant, and the formation possibility of star polymers from copolymerization of TT with PZ and EGDA was very low. In the GPC curve of the polymer formed at $6 \mathrm{~h}$ polymerization, we can see two peaks in Figure $3 b$, one at low molecular weight position is linear poly(EGDA-PZ), and other at higher molecular weight position might be the star-shaped polymers. 
When around $91.5 \%$ of vinyl group was converted (Figure 2A), the reaction probability of vinyl groups in the multifunctional TT with amine at the end of linear oligomer chains was increasing, and the star polymers were formed. With the progress of polymerization, the peak at low molecular weight position decreased, the peak at high molecular weight position increased gradually and its shift to higher molecular weight was observed (Figure $3 \mathrm{c}$ and $3 \mathrm{~d}$ ). This might imply that more linear chains were attached to the multifunctional TT with growth of the linear poly(EGDAPZ) chains. The polymer obtained at $98.9 \%$ conversion of the vinyl groups showed monomodal GPC peak as shown in Figure 3e, demonstrating that all linear polymer chains are attached to the multifunctional TT, and star-shaped polymer was formed.

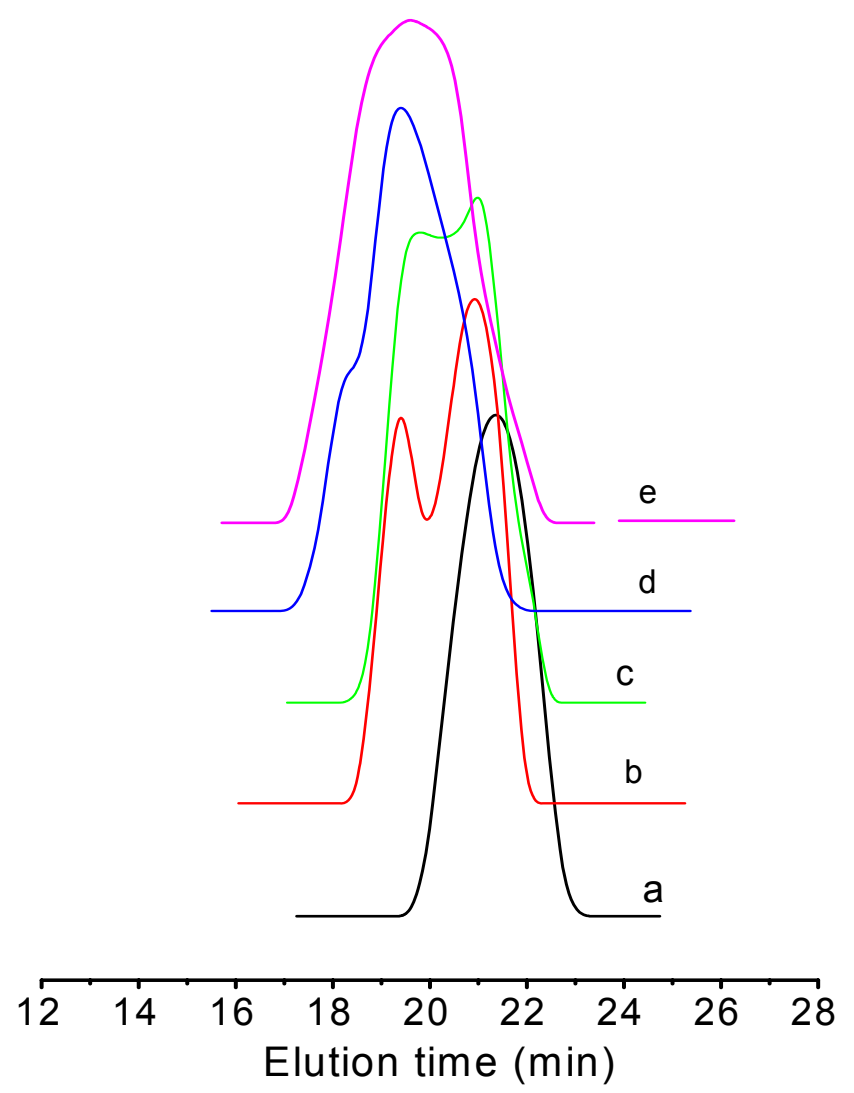

Fig. 3. GPC traces of the poly(ester amine) formed at different polymerization time: $0.5 \mathrm{~h}(\mathrm{a}) ; 6 \mathrm{~h} \mathrm{(b);} 24 \mathrm{~h}$ (c), $170 \mathrm{~h}$ (d) and $280 \mathrm{~h}$ (e). Michael addition polymerization of TT, EDGA and PZ with feed molar ratio of $1: 60: 60$ was carried out at $45^{\circ} \mathrm{C}$; the initial monomer concentration: $0.3 \mathrm{~g} / \mathrm{mL}$.

For further studying the formation process of the star-shaped polymers, ${ }^{1} \mathrm{H}$ NMR was used. Figure 4 is the ${ }^{1} \mathrm{H}$ NMR spectra of the polymers formed at various polymerization times. We can see that strength of the vinyl proton signals at $\delta=6.38$, $6.15,5.86 \mathrm{ppm}$ (a) decreased relatively with the progress of polymerization, which must result from continuous reaction of the terminal acryl group with terminal secondary amine group in the polymer chains with various chain lengths. This result is consistent with the results obtained from GPC measurements. Based on the polymerization mechanism shown in Scheme 1, every repeating unit contains one ester ethylene group, and every macromolecule has one TT unit, so number-average 
molecular weight $\left(\left[M_{\mathrm{n}}\right]_{\mathrm{s}}\right)$ of the star polymers formed can be calculated according to Eq. 2.

$$
\left[M_{\mathrm{n}}\right]_{\mathrm{s}}=\frac{256 i \dot{A}\left(I_{4.28} / 4\right)}{\left(I_{5.25} / 6\right)}+M_{\mathrm{TT}}
$$

In Eq. 2, 256 and $M_{T T}$ are the molecular weights of repeating unit and multifunctional TT. $I_{4.28}$ and $I_{5.25}$ are the integral values of the proton signals of two ester methylene groups in EGDA unit and three methylene groups of triazine in TT unit, respectively. In addition, every arm has one terminal acryl group and there is one ester ethylene group in every repeating unit, Based on integration ratio of the proton signals at $\delta=6.38,6.15,5.86 \mathrm{ppm}\left(I_{6.38}+I_{6.15}+I_{5.86}\right)$ to $4.28 \mathrm{ppm}\left(I_{4.28}\right)$, we can calculate the molecular weight $\left(\left[M_{n}\right]_{a}\right)$ of every arm according to Eq. 3.

$$
\left[M_{\mathrm{n}}\right]_{\mathrm{a}}=\frac{\left.256 i \tilde{A} / I_{4.28} / 4\right)}{\left(I_{6.38}+I_{6.15}+I_{5.86}\right) / 3}
$$

Thus the average arm number of star polymers can be estimated from dividing $\left[M_{\mathrm{n}}\right]_{\mathrm{s}}$ by $\left[M_{n}\right]_{a}$ and the results are shown in Figure 5 . As we predicted, the arm number of star polymers obtained increased with increase of vinyl group conversion. When polymerization proceeded to $98.9 \%$ conversion the arm number of the polymers obtained was $2.94\left(\left[M_{\mathrm{n}}\right]_{\mathrm{s}}=19100 \mathrm{~g} / \mathrm{mol} ;\left[M_{\mathrm{n}}\right]_{\mathrm{a}}=6500 \mathrm{~g} / \mathrm{mol}\right)$, which approaches to the theoretical value 3 . So the arm number of the star polymers is determined by the number of functional group in a multifunctional compound.

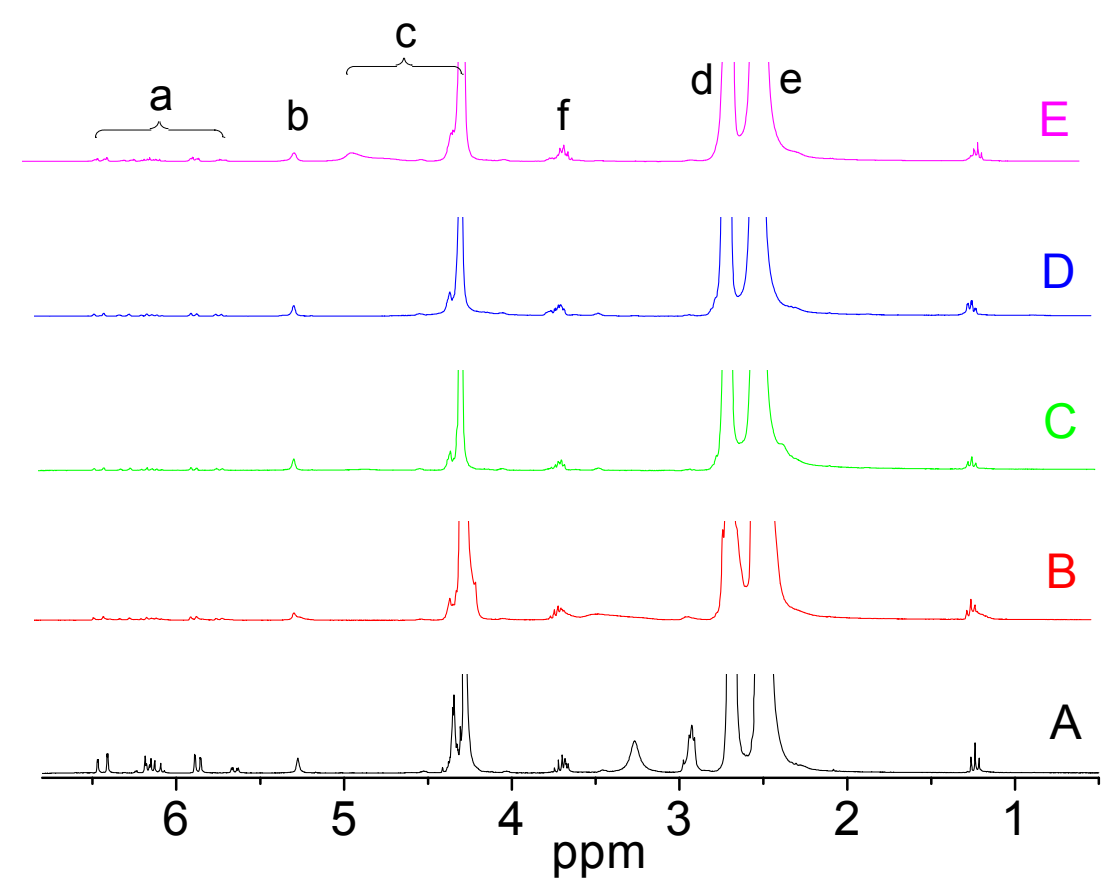

Fig. 4. ${ }^{1} \mathrm{H}$ NMR spectra of the polymers obtained at various polymerization time: 0.5 $\mathrm{h}(\mathrm{a}), 6 \mathrm{~h}$ (b), $24 \mathrm{~h}$ (b), $170 \mathrm{~h}$ (d), $280 \mathrm{~h}$ (d). Feed molar ratio of TT/EGDA/PZ $=1: 60: 60$, initial monomers concentration: $0.3 \mathrm{~g} / \mathrm{mL}$, temperature: $45^{\circ} \mathrm{C}$.

For the polymerization system of $A-B$ and $A_{f}$, when feed ratio of $A_{f}$ to $A-B$ is small and the polymerization approaches completion, $M_{\mathrm{w}} / M_{\mathrm{n}}$ can be estimated by $M_{\mathrm{w}} / M_{\mathrm{n}}=1+1 / f$, $f$ is the group number of multifunctional compound [13]. The polymer formed at initial 
stage of polymerization had relatively narrow molecular weight distribution. The molecular weight distributions of the polymers obtained at $6 \mathrm{~h}, 24 \mathrm{~h}$ and $170 \mathrm{~h}$ of polymerization are relatively broad due to coexistence of star polymers and linear poly(EGDA-PZ). When all linear chains attached to the multifunctional compound, TT, the monomodal GPC curve with $M_{\mathrm{w}} / M_{\mathrm{n}}=1.32$, which approaches to theoretical value 1.33 , was observed.

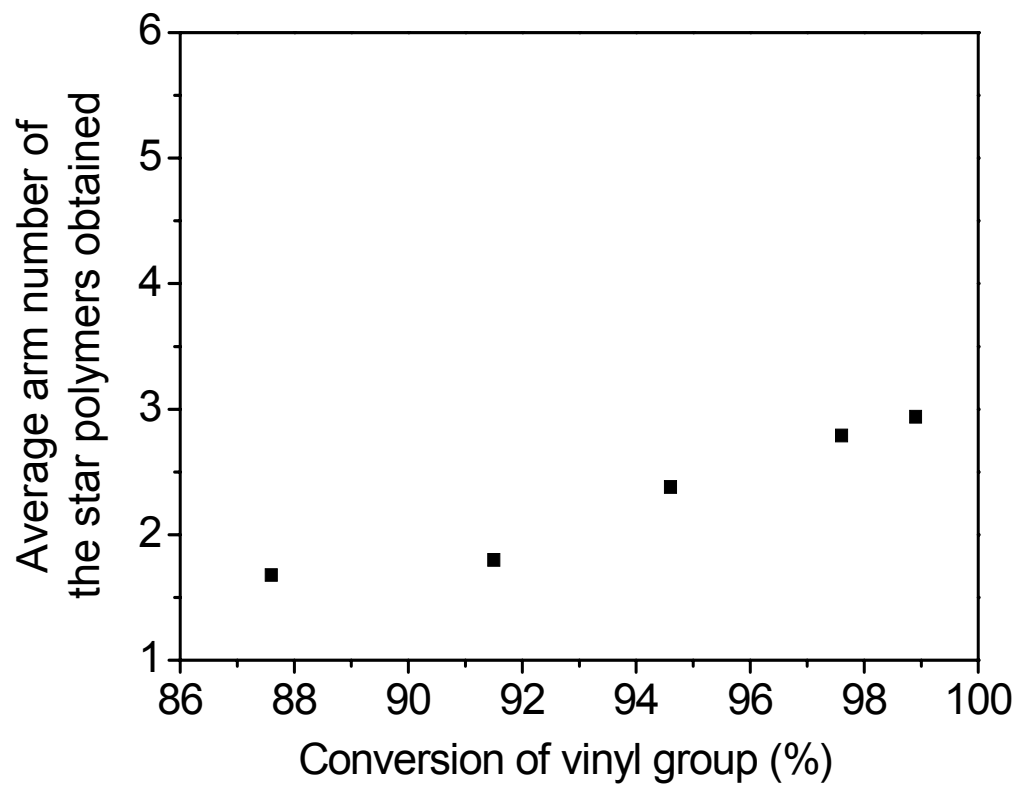

Fig. 5. The relationship of vinyl group conversion with the arm number of the star polymers obtained at various polymerization times. Michael addition polymerization of TT, EDGA and PZ with feed molar ratio of $1: 60: 60$ was carried out at $45^{\circ} \mathrm{C}$; initial monomer concentration: $0.3 \mathrm{~g} / \mathrm{mL}$.

\section{The effect of ratio of TT/PZ/EGDA on the polymerization}

For studying the effect of molar ratio of TT/PZ/EGDA on the formation of the star polymers, the Michael addition polymerization with various molar ratios of EGDA $\mathrm{PZ} / \mathrm{TT}=30: 30: 1,60: 60: 1$ and 100:100:1 and the same initial monomers concentration of $0.3 \mathrm{~g} / \mathrm{mL}$ were investigated. Their GPC spectra are shown in Figure 3, 6 and 7 respectively. In the three cases, the linear poly(EGDA-PZ) was formed at the initial stage of polymerization. Figures 3, 6 and 7 demonstrate different GPC traces of the polymers formed after $0.5 \mathrm{~h}$ of polymerization. In the case of feed molar ratio of TT/EGDA/PZ=1/30/30, there are more than 5 peaks in the GPC trace of the sample obtained from $6 \mathrm{~h}$ polymerization (Figure $6 \mathrm{~b}$ ), this may result from two or more multifunctional TT in one macromolecule in addition to the linear poly(EGDA-PZ) attaching to one TT and free linear polymer chains. During the initial stage of polymerization, some oligomers contained TT units and their further reactions should yield the polymer chains containing more than one multifunctional TT units owing to relatively high TT concentration in the feed. So it is reasonable that further reactions of these oligomers with various chain lengths produced broad molecular weight distribution polymers $\left(M_{\mathrm{w}} / M_{\mathrm{n}}=1.91\right.$ at $6 \mathrm{~h}, 2.10$ at $6 \mathrm{~h}, 3.19$ at $170 \mathrm{~h}$ in Figure 6$)$. As we mentioned, based on their ${ }^{1} \mathrm{H}$ NMR data, we can calculate the $M_{\mathrm{n}, \mathrm{NMR}}$ of the polymers obtained based on the assumption that every macromolecule has one TT unit. 


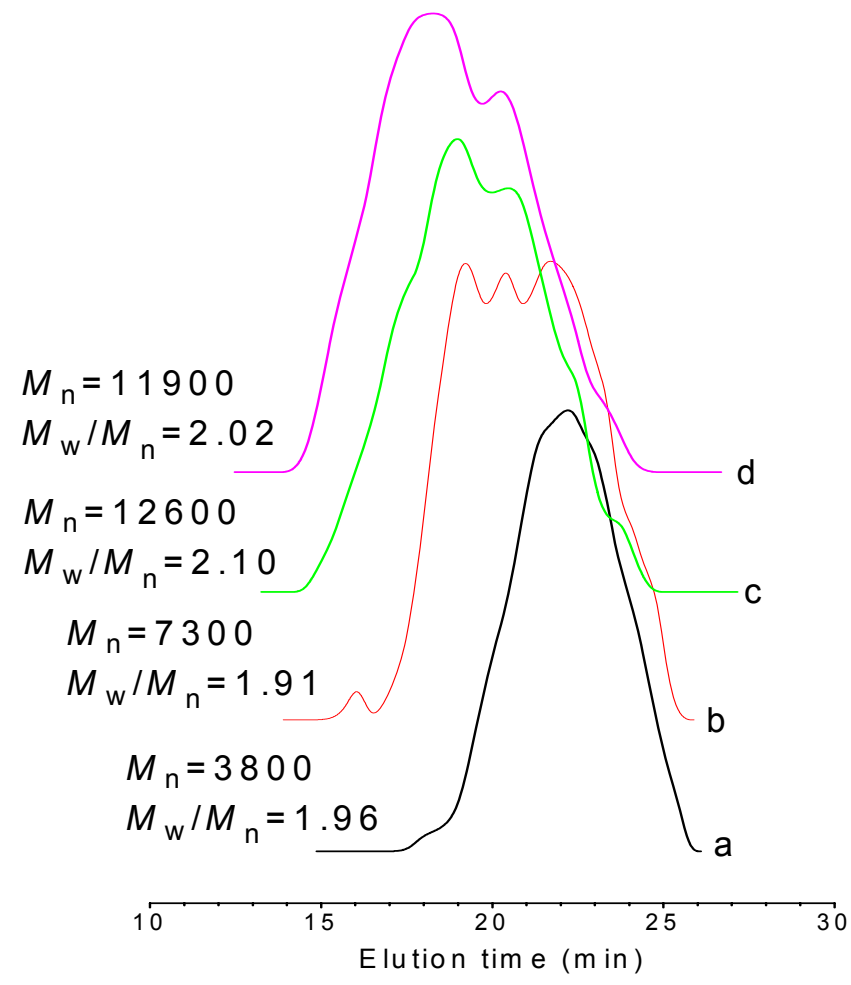

Fig. 6. GPC Traces of the poly(ester amine)s formed at different polymerization time: $0.5 \mathrm{~h} \mathrm{(a);6} \mathrm{h} \mathrm{(b);} 24 \mathrm{~h}$ (c) and $400 \mathrm{~h}$ (d). Michael addition polymerization of TT, EDGA and PZ with feed molar ratio of $1: 30: 30$ was carried out at $45{ }^{\circ} \mathrm{C}$; the initial monomers concentration: $0.3 \mathrm{~g} / \mathrm{mL}$.

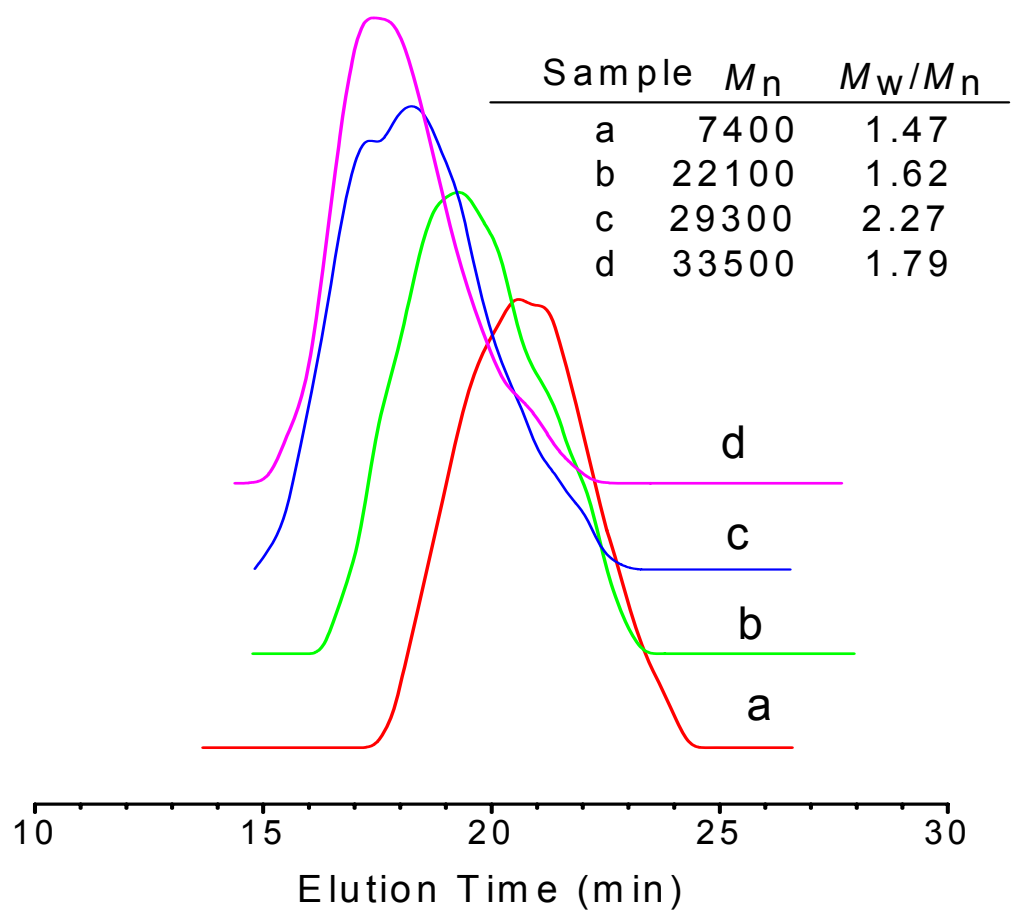

Fig. 7. GPC traces of the poly(ester amine)s formed at different polymerization time: 6 $\mathrm{h}(\mathrm{a}) ; 24 \mathrm{~h} \mathrm{(b);} 170 \mathrm{~h}$ (c) and $430 \mathrm{~h}$ (d). Michael addition polymerization of TT, EDGA and PZ with feed molar ratio of 1:100:100 was carried out at $45^{\circ} \mathrm{C}$; the initial monomers concentration: $0.3 \mathrm{~g} / \mathrm{mL}$. 
With the same assumption, the $M_{\mathrm{n}, \text { th }}$ can be calculated based on feed molar ratio and conversion (100\%). The results are listed in Table 1. Monomodal GPC trace was not obtained even after $1100 \mathrm{~h}$ polymerization. Based on these results, we thought that decreasing TT concentration will reduce the concentration of the oligomers containing more than one multifunctional TT units, and this will benefit the formation of three-armed star polymers. Figure 3 and 7 are the GPC traces of the polymers formed from the polymerization with feed molar ratios of TT/EGDA/PZ=1/60/60 and $1 / 100 / 100$ respectively. We discussed the results shown in Figure 3 already, and less peaks of the polymers formed after $6 \mathrm{~h}$ polymerization were observed in comparison with Figure 6. Probably, many linear poly(EGDA-PZ) chains capped with one acryl group and one secondary amine group, which is similar to A-B monomer, were formed, their further reaction with star oligomers having terminal acryl group produced three-armed star poly(EGDA-PZ). However, a shoulder on GPC trace of Figure $7 d$ appeared at low molecular weight position for the polymer obtained at 430 $\mathrm{h}$ of polymerization, probably, the unreacted linear oligomers still existed.

Tab. 1. Michael addition polymerization of EGDA and PZ with TT. ${ }^{a}$

\begin{tabular}{rccccccc}
\hline Entry & $\begin{array}{c}\text { Molar ratio } \\
\text { TT:EGDA:PZ }\end{array}$ & $\begin{array}{c}\text { Conc } \\
(\mathrm{g} / \mathrm{mL})\end{array}$ & $\begin{array}{c}\text { Time } \\
(\mathrm{h})\end{array}$ & $M_{\mathrm{n}, \mathrm{GPC}^{\mathrm{C}}}$ & $M_{\mathrm{w}} / M_{n}{ }^{\mathrm{C}}$ & {$\left[M_{\mathrm{n}, \mathrm{NMR}]_{\mathrm{s}}{ }^{\mathrm{d}}}\right.$} & $M_{\mathrm{n}, \mathrm{th}}{ }^{\mathrm{e}}$ \\
\hline B-5 & 1: $60: 60$ & 0.6 & 6 & 15000 & 1.22 & 15200 & 15600 \\
B-6 $^{\mathrm{b}}$ & 1: $60: 60$ & 0.6 & 24 & - & - & - & - \\
C-7 & 1: $30: 30$ & 0.3 & 0.5 & 3800 & 1.96 & 6900 & 7900 \\
C-8 & 1: $30: 30$ & 0.3 & 6 & 7300 & 1.91 & 7300 & 7900 \\
C-9 & 1: $30: 30$ & 0.3 & 24 & 12600 & 2.10 & 7500 & 7900 \\
C-10 & 1: 30: 30 & 0.3 & 400 & 11900 & 2.02 & 8400 & 7900 \\
D-11 & 1: $100: 100$ & 0.3 & 6 & 7400 & 1.47 & 23500 & 25800 \\
D-12 & 1: $100: 100$ & 0.3 & 24 & 22100 & 1.62 & 24500 & 25800 \\
D-13 & 1: $100: 100$ & 0.3 & 170 & 29300 & 2.27 & 25300 & 25800 \\
D-14 & 1: $100: 100$ & 0.3 & 430 & 33500 & 1.79 & 26800 & 25800 \\
\hline
\end{tabular}

a) Polymerization condition: $45^{\circ} \mathrm{C}$; solvent: $\mathrm{CHCl}_{3}$.

b) Gelled after $24 \mathrm{~h}$ of polymerization.

c) Measured by GPC method.

d) Calculated according to eq 2 .

e) Calculated according to $M_{n, t h}=([E G D A] /[T T]) \times$ conversion $\times M+M_{T T}, M$ and $M_{T T}$ are the molecular weights of repeating unit and TT, conversion is $100 \%$, this equation is based on the assumption that every molecule has one TT unit.

\section{The effect of solution concentration on the polymerization}

Generally, the Michael addition polymerization of acryl- and amine-terminated monomers in high monomer concentration proceeds relatively fast. Thus we tested the influence of monomer concentration on the polymerizations. The polymerization with the feed molar ratio of EGDA/PZ/TT=1/60/60 was carried out in the $60 \%(\mathrm{w} / \mathrm{v})$ monomer concentration. The condition and results are listed in Table 1. After $6 \mathrm{~h}$ polymerization, the $M_{\mathrm{n}, \mathrm{NMR}}$ of the polymers obtained approached the $M_{\mathrm{n}, \mathrm{th}}$ (B-5 in Table 1), indicating almost completion of polymerization. However, a small portion of low molecular weight component remained in the polymerization system. When the polymerization proceeded for $24 \mathrm{~h}$, we found that light cross-linked polymers were formed. Probably, fast polymerization left more A-A monomers or oligomers, leading to the crosslinking reaction of three armed polymers. 


\section{Conclusions}

Three-armed star poly(ester amine) can be synthesized by Michael addition polymerizations of equal molar ratio of EGDA and PZ with a small proportion of multifunctional TT. The molecular weight of the polymer obtained was determined by the feed molar ratio of EGDA or PZ to TT. High monomer concentration resulted in high polymerization rate, but pure star polymer was not obtained, and lightly crosslinked polymer was formed after slightly long polymerization time. For the polymerization with feed molar ratio of TT/EGDA/PZ=1/30/30, the GPC traces obtained at $6 \mathrm{~h}$ and $400 \mathrm{~h}$ polymerization shows that more than 5 polymer components reduced to two components. Thus this provides a feasible and convenient synthetic strategy for star polymers

\section{Experimental}

\section{Materials}

THF was distilled from a purple sodium ketyl solution. Styrene (St) was distilled from calcium hydride. Triethylamine was stirred over anhydrous magnesium sulfate and filtered just prior to use. Ethylene glycol was stirred over anhydrous magnesium sulfate, filtered and stored over $4 \AA$ molecular sieves. $\mathrm{CHCl}_{3}$ (Shanghai Chemical Reagent; 99\%) was dried under $\mathrm{CaCl}_{2}$ for $6 \mathrm{~h}$ after washing with water and then was distilled prior to use. 1,3,5-Triacryloylhexahydro-1,3,5-triazine (Aldrich, 99\%) was used as received. Acryl chloride, methylene chloride, $\mathrm{NaHCO}_{3}$, magnesium, acetone, ethylenediamine, perchloric acid $(60 \%), \mathrm{NaBH}_{4}$, sodium hydroxide, piperazine (PZ) and diethylene triamine, which all were purchased from Shanghai Chemical Reagent Corp., were used as received. Ethylene glycol diacrylate (EGDA) was synthesized by a similar method described in a previous paper [21]. ${ }^{1} \mathrm{H} \mathrm{NMR}\left(\mathrm{CDCl}_{3}, \mathrm{TMS}\right): \delta=6.46$ $(2 \mathrm{H}$, cis $\mathrm{CHH}=\mathrm{CH}), 5.84(2 \mathrm{H}$, trans $\mathrm{CHH}=\mathrm{CH}), 6.15\left(2 \mathrm{H}, \mathrm{OOCCH}=\mathrm{CH}_{2}\right), 4.41(4 \mathrm{H}$, $\mathrm{COOCH}_{2}-\mathrm{CH}_{2} \mathrm{OOC}-$ ).

\section{Polymerization of EDGA and PZ in the presence of TT}

Michael addition polymerization with various feed ratios was carried out and a typical polymerization procedure is as follows. PZ (992 $\mathrm{mg}, 11.5 \mathrm{mmol})$ and EGDA (1960 $\mathrm{mg}, 11.5 \mathrm{mmol}$ ) were added into a solution of TT (48 mg, $0.193 \mathrm{mmol})$ in chloroform $(10 \mathrm{~mL})$, and the polymerization was performed at $45^{\circ} \mathrm{C}$. At predetermined polymerization time intervals, a sample was taken for GPC and ${ }^{1} \mathrm{H}$ NMR measurements. When the GPC curve became unimodal, the polymerization was stopped. The reaction solution was concentrated under reduced pressure, and the residue was poured into cold acetone. The resultant solid product was collected by filtration, and dried in a vacuum oven at $50{ }^{\circ} \mathrm{C}$ for $24 \mathrm{~h} .{ }^{1} \mathrm{H} \mathrm{NMR}\left(\mathrm{CDCl}_{3}, \mathrm{TMS}\right)$ : $\delta=6.38($ cis $\mathrm{CHH}=\mathrm{CH}), 5.86(\mathrm{H}$, trans $\mathrm{CHH}=\mathrm{CH}), 6.12\left(\mathrm{OOCCH}=\mathrm{CH}_{2}\right), 5.25\left(-\mathrm{NCH}_{2} \mathrm{~N}-\right.$ in TT ring), $4.3\left(\mathrm{COOCH}_{2} \mathrm{CH}_{2} \mathrm{OOC}\right), 2.5 \sim 2.67\left(\mathrm{NCH}_{2} \mathrm{CH}_{2} \mathrm{~N}\right.$ in $\mathrm{PZ}$ ring, $\mathrm{OOCCH}_{2} \mathrm{CH}_{2} \mathrm{~N}$ ). Other four polymerizations were performed with the same procedure except the feed molar ratios, for sample B, TT (48 mg), EDGA (1960 mg), PZ (992 $\mathrm{mg}$ ), $5 \mathrm{~mL} \mathrm{CHCl}$; for sample C, TT (48 mg), EDGA (980 mg), PZ (496 mg), $10 \mathrm{~mL}$ $\mathrm{CHCl}_{3}$; for sample D, TT (96 mg), EDGA (1960 mg), PZ (994 mg), $10 \mathrm{~mL} \mathrm{CHCl} 3$; for sample E, TT (29 mg), EDGA (1980 mg), PZ (1001 mg), $10 \mathrm{~mL} \mathrm{CHCl}$. 


\section{Following the polymerization using NMR method}

TT, EGDA and PZ with feed molar ratio=1:60:60 were dissolved in $\mathrm{CDCl}_{3}$ and the reaction solution with the concentration of around $30 \%(\mathrm{w} / \mathrm{v})$ was added into a NMR tube. The reaction was carried out at $45^{\circ} \mathrm{C}$. The ${ }^{1} \mathrm{H}$ NMR spectra were recorded at a predetermined reaction time interval.

\section{The effect of monomer concentration on the polymerization}

The procedure for studying monomer concentration during polymerization is as follows. PZ (992 mg, $11.5 \mathrm{mmol}$ ) and EGDA (1960 mg, $11.5 \mathrm{mmol}$ ) were added into a TT (48 mg, $0.193 \mathrm{mmol}$ ) solution in $10 \mathrm{~mL}$ or $5 \mathrm{~mL} \mathrm{CHCl} 3$ respectively. After all reactants were dissolved, the reaction solutions with monomer concentration of $30 \%$, or $60 \%(\mathrm{w} / \mathrm{v})$ were made. The polymerization was carried out at $45{ }^{\circ} \mathrm{C}$. At predetermined polymerization time intervals, a sample was taken for GPC measurement. The polymerization stopped until unimodal GPC trace was obtained. For polymerization with feed molar ratio of TT:EGDA:PZ = 1:30:30 and monomer concentration of $30 \%(\mathrm{w} / \mathrm{v})$, the same procedure was adopted.

\section{Characterization}

${ }^{1} \mathrm{H}$ NMR $(300 \mathrm{MHz})$ spectra were recorded on a Bruker 300 nuclear magnetic resonance (NMR) instrument, using $\mathrm{CDCl}_{3}$ as solvent and tetramethylsilane (TMS) as internal reference. The molecular weight, $M_{n}(\mathrm{GPC})$ and molecular weight distribution $\left(M_{\mathrm{w}} / M_{\mathrm{n}}\right)$ were determined on a Waters 515 gel permeation chromatography (GPC) equipped with microstyragel columns $\left(500,10^{3}\right.$ and $\left.10^{4} \AA\right)$ at $25^{\circ} \mathrm{C}$. Monodispersed polystyrenes standards were used in the calibration of molecular weight and molecular weight distribution, and THF was used as eluent at a flow rate of 1.0 $\mathrm{mL} / \mathrm{min}$. Infrared spectra were recorded on a Bruker VECTOR-22 infrared spectrometer.

\section{Acknowledgements}

This work is supported by the National Natural Science Foundation of China under contract No. 50673086 and 50633010.

\section{References}

[1] Zhang, X.; Xia, J.; Matyjaszewski, K. Macromolecules 2000, 33, 2340.

[2] Bosman, A. W.; Vestberg, R.; Heumann, A.; Fre'chet, J. M. J.; Hawker, C. J. J. Am. Chem. Soc. 2003, 125, 715.

[3] Jacob, S.; Majoros, I.; Kennedy, J. P. Macromolecules 1996, 29, 8631.

[4] Matyjaszewski, K.; Miller, P. J.; Fossum, E.; Nakagawa, Y. Appl. Organomet. Chem. 1998, 12, 667.

[5] Liu Y; Pan C. Y. J. Polym. Sci., Part A: Polym. Chem. 1997, 35, 3403.

[6] Xia, J.; Zhang, X.; Matyjaszewski, K. Macromolecules 1999, 32, 4482.

[7] Rein, D.; Rempp, P.; Lutz, P. J. Makromol. Chem. Macromol. Symp. 1993, 67, 237.

[8] Kanaoka, S.; Sawamoto, M.; Higashimura, T. Macromolecules 1991, 24, 2309.

[9] Sugi, R.; Hitaka, Y.; Yokoyama, A.; Yokozawa, T. Macromolecules 2005, 38, 5526.

[10] Nelson, J.M.; Allcock, H.R. Macromolecules 1997, 30, 1854. 
[11] Kricheldorf, H. R.; Stukenbrock, T.; Friedrich, C. J. Polym. Sci., Part A: Polym. Chem. 1998, 36, 1387.

[12] Honda, K.; Maruyama, T.; Yamamoto, T. Synth. Met. 1997, 90, 153.

[13] Schaefgen, J. R.; Flory, P. J. J. Am. Chem. Soc. 1948, 70, 2709.

[14] Flory, P.J. J. Am. Chem. Soc. 1937, 59, 241.

[15] Kono, K.; Liu, M.; Fréchet, J. M. J. Bioconjugate Chem. 1999, 10, 1115-1121.

[16] Yang, H.; Morris, J. J.; Lopina, S. T. J. Colloid Interface Sci. 2004, 273, 148-154.

[17] Choi, J. S.; Ko, K. S.; Park, J. S.; Kim, Y. H.; Kim, S. W.; Lee, M. Int. J. Pharm. 2006, 320, 171-178.

[18] Wang, D. Zheng, Z. J.; Hong, C. Y.; Liu, Y.; Pan, C. Y. J. Polym. Sci., Part A: Polym. Chem. 2006, 44, 6226-6242.

[19] Wang, D.; Liu, Y.; Hu, Z.; Hong, C.; Pan, C. Y. Polymer 2005, 46, 3507.

[20] Wang, D.; Liu, Y.; Hu, Z.; Hong, C.; Pan, C. Y. J. Polym. Sci., Part A: Polym. Chem. 2005, 43, 5127.

[21] Zheng, G. H.; Zheng, Q.; Pan, C. Y. Macromol. Chem. Phys. 2006, 207, 216223. 